\title{
Comprehensive Analysis on the Hydrologic Alteration and Causes of River Runoff in Min River of the Yangtze River, China
}

\section{Wenxian Guo}

North China University of Water Resources and Electric Power Haotong Zhou

North China University of Water Resources and Electric Power

Xuyang Jiao

North China University of Water Resources and Electric Power

Yongwei Zhu

North China University of Water Resources and Electric Power

Hongxiang Wang ( $\nabla$ wanghongxiang@ncwu.edu.cn )

North China University of Water Resources and Electric Power

\section{Research Article}

Keywords: Min River, IHA-RVA, Budyko, Climate Alteration, Human Activities

Posted Date: January 6th, 2022

DOI: https://doi.org/10.21203/rs.3.rs-1213793/v1

License: (c) (1) This work is licensed under a Creative Commons Attribution 4.0 International License. Read Full License 


\title{
Comprehensive analysis on the hydrologic alteration and causes
}

\section{of river runoff in Min River of the Yangtze River, China}

\author{
Wenxian $\mathrm{Guo}^{1}$, Haotong Zhou ${ }^{1}$, Xuyang Jiao ${ }^{1}$, Yongwei Zhu², Hongxiang Wang ${ }^{2}$, * \\ (1. College of Water Resources, North China University of Water Resources and Electric Power, \\ Zhengzhou 450045, China. 2. School of Water Conservancy, North China University of Water \\ Resources and Electric Power, Zhengzhou 450045, China. Correspondence and requests for materials \\ should be addressed to H.W. (email: wanghongxiang@ncwu.edu.cn))
}

\begin{abstract}
The construction of water conservancy projects has changed the hydrological situation of rivers and has an essential impact on the river ecosystem. The influence modes of different factors on runoff alteration are discussed to improve the development and utilization of water resources and promote ecological benefits. The ecological, hydrological index change range method (IHA-RVA) and hydrological alteration degree method were comprehensively used to evaluate Min River's hydrological situation. Based on six budyko hypothesis formulas, the contribution rates of climate change and human activities to runoff change are quantitatively analyzed. The study showed that the runoff of Min River basin showed a significant decreasing trend from 1960 to 2019 and a sudden alteration around 1993; The overall alteration in runoff conditions was $45 \%$ moderate, and the overall alteration in precipitation was $37 \%$ moderate; Precipitation and potential evapotranspiration also showed a decreasing trend within the same period, but the overall trend was not significant; The contribution of climate alteration to runoff alteration is $30.2 \%$, and the contribution of human activities to runoff alteration is $69.8 \%$, human activities are the dominant factor affecting the alteration of runoff situation in Min River basin.
\end{abstract}

Keywords: Min River; IHA-RVA; Budyko; Climate Alteration; Human Activities Introduction

Hydrological conditions are critical drivers of riverine ecosystems and play an essential role in maintaining the energy processes, biological interactions, and physical habitat conditions ${ }^{1}$. Climate alteration and human activities are two critical factors influencing runoff alterations. The runoff formation is closely related to climate alteration in terms of precipitation and potential evapotranspiration; the impact of human activities can also cause alterations in runoff in the watershed ${ }^{2,3}$. In recent decades, extreme weather and climate events have brought frequent floods to the Min River basin area. In contrast, the superimposed effects of many human activities and the construction of large water conservancy projects have played a regulatory role in river runoff, changing the river's runoff and its original seasonal and intra-annual distribution ${ }^{4,5}$. These alterations will directly or indirectly affect the habitat waters and habits of biological resources in the watershed, thus affecting the distribution of habitat quality in the watershed ${ }^{6}$. The Min River is one of the important tributaries of the upper reaches of the Yangtze River and has very rich resources. In recent years, as my country's comprehensive national strength has increased, the construction of the Min Reservoir has gradually been paid attention to, and a group of cascade reservoirs including series-parallel mixed-connection has been formed ${ }^{7,8}$. The construction of the reservoir will have an impact on the climate in the Min River Basin, which will inevitably alteration the runoff and cause certain disturbances to the ecosystem in the basin ${ }^{9,10}$. The study of hydrological alterations in the Min River basin is essential for ecological restoration and sustainable development of the upper Yangtze River basin. 
With the development and construction of large-scale reservoirs in the Min River basin, there is a tendency for its runoff to decrease. The extent of runoff alteration and its influencing factors have been a hot research topic by scholars and abroad. The most widely used method is the Range of Variability Approach (RVA), which Richter ${ }^{11,12}$ proposes to analyze the overall hydrological alterations of rivers. In recent years, many scholars have discussed this issue. Gao et al. ${ }^{13}$ used ecological streamflow indicators and IHA indicators to analyze the alterations in the Yangtze River's hydrological conditions and quantitatively separate the effects of reservoir operation and climate alteration on runoff. Guo et al. ${ }^{14}$ used the cumulative slope alteration method to investigate climate alteration and anthropogenic factors in the Yangtze River mainstem, and this study did not consider climate factors such as wind speed and temperature, lacking accuracy. Xia et al. ${ }^{15}$ quantitatively estimated runoff alterations in the upper reaches of the Han River based on the elastic coefficient method and hydrological simulation method and discussed the differences in runoff caused by natural and artificial factors, studies have shown that human activities have a more significant impact on runoff. In recent years, for the attribution analysis of river runoff alterations, there are mainly hydrological simulation methods, climate elasticity coefficient methods, and double cumulative curve methods to explore the influence of climate alteration and human activity factors on runoff alterations. Many scholars have used hydro-meteorological data to fit the empirical relationships of water-heat balance in different basin types to confirm the validity of Budyko's hypothesis, and the method is widely used in globally important river basins ${ }^{16,19}$. This study mainly focuses on the methods of IHA-RVA and elasticity coefficient method, and the results can better reflect the degree of runoff alteration and influencing factors.

Many scholars from different perspectives have discussed the impact of Min river runoff alteration. Hou et al. ${ }^{20}$ used a dual-mass mean curve (DMC) and distributed time-varying gain hydrological model (DTVGM) to distinguish the effects of climate alteration and human activities on water resources. Mao et al. ${ }^{21}$ used soil and water assessment tools to develop a regional model to divide the Min River basin into 236 sub-basins, through GIS-based image display, simulations showed the spatial runoff of each sub-basin distribution. They analyzed the impact of land-use alteration on runoff. Guo et al. ${ }^{22}$ firstly restored the natural runoff process at Gaochang station in the Min River basin, simulated the commissioning scenario of Shuangjiangkou reservoir, and predicted the variability of the hydrological situation at Gaochang station. The analysis of runoff alterations and their factors in the Min River basin has been limited to the study of trends and abrupt alterations, but there is a lack of in-depth research on the causes of alterations in hydrological indicators before and after abrupt alterations in runoff and the effects of alterations in habitat quality on runoff. The composition, structure, and function of ecosystems such as rivers and wetlands are inextricably linked to their hydrological characteristics, and alterations in land use can impact the spatial and temporal distribution of water resources by altering the hydrological cycle of runoff $\mathrm{f}^{23,24}$. At the same time, further research is needed on such issues because of the lack of qualitative analysis of the effects of alterations in hydrological conditions on organisms in the Min River basin due to the lack of information on aquatic biota in the basin.

In this paper, based on the previous studies, we use the ecohydrological index range of alteration (IHA-RVA) and hydrological alteration method to evaluate the hydrological situation in the Min River basin and analyze the degree of influence of climate alteration and human activities on runoff in the Min River basin in a more objective way. FAO Penman-Monteith formula was used to calculate the potential evapotranspiration in Min River Basin. According to the long-term 
water balance formula, drying index, and six Budyko hypothesis formulas, the influence of climate change and human activities on runoff was calculated. This study provides a reference for the Min River basin to cope with climate alteration and develop and utilize water resources more rationally.

\section{Results and Analysis Mutagenicity analysis}

The Mann-Kendall nonparametric test, the sliding t-test, and the cumulative distance level method were applied to the annual runoff and annual precipitation to test the abrupt alterations of their intra-annual long series (Figure 1). The intersection of the UF and UB statistics of runoff and precipitation is at 0.05 significant level, and that of precipitation is at 0.1 significant level, which indicates that the hydrological situation of the Min River basin may have changed abruptly in 1993 and 1997. The results of the sliding t-test method can be concluded that the intra-annual distribution uniformity of runoff volume passes the 0.05 significant level, and the intra-annual distribution uniformity of precipitation volume does not pass the 0.1 significant level. From the figure, it can be seen that the annual runoff volume showed abrupt alterations in 1968 and 1993, and the years of abrupt alterations in annual precipitation were 1990 and 1993. The cumulative anomaly method shows that the annual runoff had a maximum value in 1993 and 2002, and the annual precipitation had a maximum value in 1974. Combining the above three methods, 1993 was chosen as the year of the sudden alteration in annual runoff and annual precipitation in this study. The daily runoff data from Gaochang hydrological station and daily precipitation data from the Min River basin were divided into a base period $T_{a}(1960 \sim 1993)$ and a alteration period $T_{b}$ (1994 2019).
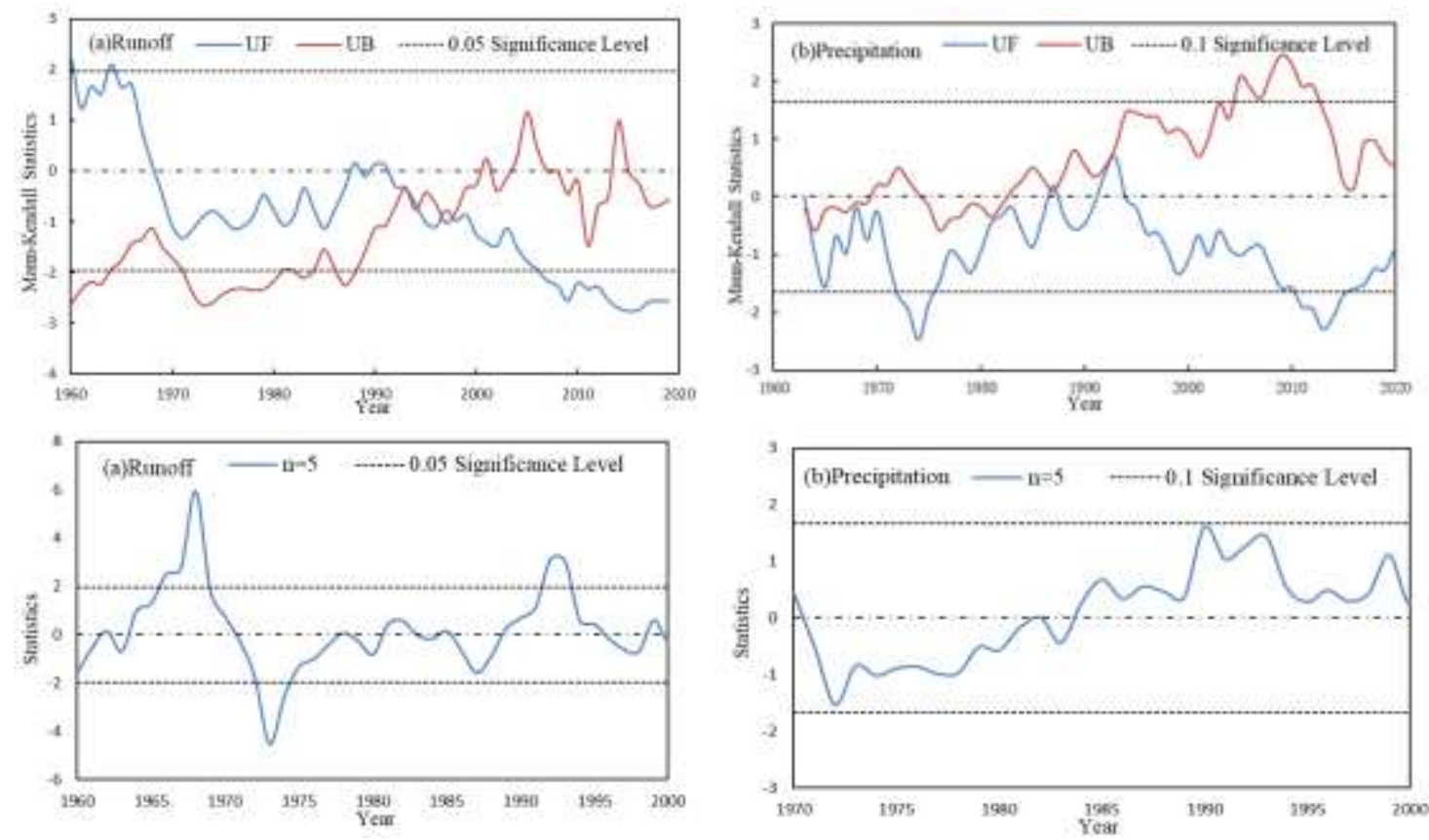

Fig.1 Mutation test analysis curve

Table.1 Years of sudden alteration in uniformity of runoff and precipitation distribution throughout the year

\begin{tabular}{ccccc}
\hline Method & Mann-Kendall & Sliding T-test & $\begin{array}{c}\text { Cumulative } \\
\text { distance level }\end{array}$ & Mutation year \\
\hline Runoff & 1993、1997 & 1968、1993 & $1993 、 2002$ & 1993 \\
\hline
\end{tabular}




\section{IHA hydrological index alteration degree analysis}

113

As climate alteration and human activities are important factors affecting runoff alterations, considering only daily flow alterations can only describe the changing state of the Min River basin at a macroscopic level, and to further analyze the causes of runoff alterations in a more detailed way, the recording, and analysis of climate alteration data are essential. Precipitation has a direct impact on runoff alterations in climate alteration. Considering daily precipitation data, it can reflect not only the rise and fall of rivers directly but also the alterations of aquatic organisms and riparian habitats. Therefore, in this study, the RVA method was used to analyze the daily streamflow data of Gaochang Station, a representative hydrological station of Min River, and the daily precipitation data of 13 meteorological stations in the Min River basin for variability analysis. Combining the above analyses, the daily streamflow data from the Gaochang station and the daily precipitation data from the Min River basin were divided into the base period $\mathrm{T}_{\mathrm{a}}$ (1960 1993) and the abrupt alteration period $\mathrm{T}_{b}$ (1994 2019), and the alteration rates and degrees of alteration of 32 parameters were calculated (Table 2) to quantitatively assess the alterations in the streamflow situation in the Min River basin.

(1) The average flow and precipitation of each month. As can be seen from Table 2, the average monthly flow at the Gaochang hydrological station increased to different degrees after the abrupt alteration, while the average monthly precipitation in the Min River basin increased and decreased, but the increase and decrease were more moderate; the flood season of the Min River was concentrated in June to September, and the rate of alteration of streamflow and precipitation in this period was relatively large; the alteration of average monthly flow was high in May, and medium and low in the rest of the month; for the alteration of average monthly precipitation, July was high. After 1993, the number of reservoirs and their capacity increased significantly, which increased the post-surge flow and caused some disturbance to aquatic organisms' reproduction.

(2) Annual extreme flow and precipitation. The annual mean extreme minimum flow at the Min River basin high field hydrological stations generally increased after the abrupt alteration, while the extreme values showed different degrees of decrease, of which the minimum 7-day flow was highly altered, and the rest were moderately and lowly altered. The reservoir construction and operation after 1993 affected the original flow polarity alteration process of the river. The range of annual extreme precipitation alteration is more drastic, which influences the flow alteration. Such extreme daily alterations in precipitation are frequent and unpredictable, and extreme alterations in precipitation can lead to alterations in natural river hydrologic processes, causing disturbances to species that are not adapted to frequent alterations in water flow.

(3) The timing of annual extreme flow and precipitation occurrence. After the sudden hydrology alteration at the high field hydrological station, the occurrence time of annual maximum flow and annual minimum flow was changed at a low degree, indicating that the alteration of hydrological indicators in this group had a little alteration on biological abundance. The annual precipitation alterations were low, and climate alteration had no significant effect on the occurrence time of annual extreme flow.

(4) Frequency and ephemeris of high and low flows with precipitation. After the abrupt alteration, the number of low flow pulses and the rate of alteration of flow low pulse ephemeris is increased by $25 \%$. The number of flow pulses is moderately altered, and the pulse ephemeris is lowly altered. The rate of alteration of precipitation is less than $10 \%$ in all cases, which is a small 
effect. The alterations of high and low durations will affect the structure and function of river ecosystem, alteration the soil moisture content on both sides of the river, and disappear the riparian vegetation.

(5) The rate of alteration and frequency alteration of flow and precipitation. After the abrupt alteration, the rate of flow increases, and the number of reversals have different degrees of increase, and the rate of flow decrease reaches $100 \%$ as high alteration, which makes the allowable range of flow alteration decrease. The annual precipitation decline rate of $78 \%$ is highly altered, and the annual precipitation reversal number of 38\% reaches moderate alteration, indicating that climate alteration has a certain impact on the flow alteration rate and frequency alteration. The rate and frequency of flow alterations affect the pattern of river rise and fall, thus affecting the survival and reproduction of aquatic organisms. The ecosystem has a limited ability to withstand external alterations, and a reduced range of flow alterations can affect the growth of organisms on both sides of the river, while too frequent flows can destabilize flora and fauna.

\begin{tabular}{|c|c|c|c|c|c|c|c|c|}
\hline \multirow{2}{*}{ IHA Indicators } & \multicolumn{2}{|c|}{ Pre-Impact 1960-1993 } & \multicolumn{2}{|c|}{ Post-Impact 1994-2019 } & \multicolumn{2}{|c|}{ Rata/\% } & \multicolumn{2}{|c|}{ Variability $/ \%$} \\
\hline & flow & Precipitation & flow & Precipitation & flow & Precipitation & flow & Precipitation \\
\hline January & 758.5 & 0.135 & 836.5 & 0.117 & $17 \%$ & $13 \%$ & $-43(\mathrm{M})$ & $-30(\mathrm{~L})$ \\
\hline February & 709 & 0.27 & 788.5 & 0.229 & $21 \%$ & $15 \%$ & $-43(\mathrm{M})$ & $-22(\mathrm{~L})$ \\
\hline March & 819 & 0.558 & 965.5 & 0.535 & $8 \%$ & $4 \%$ & $-10(\mathrm{~L})$ & $-11(\mathrm{~L})$ \\
\hline April & 1053 & 1.282 & 1268 & 1.423 & $2 \%$ & $11 \%$ & $-21(\mathrm{~L})$ & $-11(\mathrm{~L})$ \\
\hline May & 1990 & 2.535 & 1840 & 2.435 & $16 \%$ & $4 \%$ & $-77(\mathrm{H})$ & $-44(\mathrm{M})$ \\
\hline June & 3470 & 4.314 & 3390 & 4.509 & $18 \%$ & $5 \%$ & $-21(\mathrm{~L})$ & $-22(\mathrm{~L})$ \\
\hline July & 5615 & 5.077 & 4710 & 4.405 & $20 \%$ & $13 \%$ & $-55(\mathrm{M})$ & $-78(\mathrm{H})$ \\
\hline August & 5230 & 4.805 & 4310 & 3.988 & $12 \%$ & $17 \%$ & $-43(\mathrm{M})$ & $-22(\mathrm{~L})$ \\
\hline September & 4875 & 3.965 & 3905 & 3.573 & $12 \%$ & $10 \%$ & $-36(\mathrm{M})$ & $11(\mathrm{~L})$ \\
\hline October & 3095 & 1.464 & 2725 & 1.3 & $1 \%$ & $11 \%$ & $-21(\mathrm{~L})$ & $56(\mathrm{M})$ \\
\hline November & 1755 & 0.323 & 1540 & 0.311 & $3 \%$ & $4 \%$ & $-55(\mathrm{M})$ & $11(\mathrm{~L})$ \\
\hline December & 1130 & 0.125 & 1145 & 0.1 & $7 \%$ & $20 \%$ & $-44(\mathrm{M})$ & $33(\mathrm{M})$ \\
\hline $\begin{array}{l}\text { 1-day } \\
\text { minimum }\end{array}$ & 578.5 & 0 & 598.5 & 0 & $13 \%$ & 0 & $-21(\mathrm{~L})$ & $3(\mathrm{~L})$ \\
\hline $\begin{array}{l}\text { 3-day } \\
\text { minimum }\end{array}$ & 601.8 & 0.007 & 645.5 & 0 & $12 \%$ & $100 \%$ & $-55(\mathrm{M})$ & $56(\mathrm{M})$ \\
\hline $\begin{array}{l}\text { 7-day } \\
\text { minimum }\end{array}$ & 625.4 & 0.041 & 705.1 & 0.0241 & $10 \%$ & $42 \%$ & $-67(\mathrm{H})$ & $22(\mathrm{~L})$ \\
\hline 30-day & 677.2 & 0.180 & 760.7 & 0.142 & $19 \%$ & $21 \%$ & $-43(\mathrm{M})$ & $22(\mathrm{~L})$ \\
\hline $\begin{array}{l}\text { 90-day } \\
\text { minimum }\end{array}$ & 780.9 & 0.472 & 864.3 & 0.511 & $21 \%$ & $8 \%$ & $-43(\mathrm{M})$ & $22(\mathrm{~L})$ \\
\hline $\begin{array}{c}\text { 1-day } \\
\text { maximum }\end{array}$ & 16050 & 23.41 & 12950 & 23.47 & $20 \%$ & 0 & $-47(\mathrm{M})$ & 44(M) \\
\hline $\begin{array}{l}\text { 3-day } \\
\text { maximum }\end{array}$ & 12620 & 14.58 & 9967 & 13.27 & $20 \%$ & $9 \%$ & $-32(\mathrm{~L})$ & 44(M) \\
\hline 7-day & 9877 & 10.34 & 7886 & 10.17 & $18 \%$ & $2 \%$ & $-32(\mathrm{~L})$ & $44(\mathrm{M})$ \\
\hline
\end{tabular}




\begin{tabular}{|c|c|c|c|c|c|c|c|c|c|}
\hline & $\begin{array}{l}\text { 30-day } \\
\text { maximum }\end{array}$ & 7436 & 7.182 & 5927 & 7.309 & $28 \%$ & $2 \%$ & $-32(\mathrm{~L})$ & $-11(\mathrm{~L})$ \\
\hline & $\begin{array}{l}\text { 90-day } \\
\text { maximum }\end{array}$ & 5857 & 6.028 & 4802 & 5.81 & $3 \%$ & $4 \%$ & $-43(\mathrm{M})$ & $11(\mathrm{~L})$ \\
\hline & $\begin{array}{c}\text { Baseflow } \\
\text { index }\end{array}$ & 0.2272 & 5 & 0.291 & 12 & $1 \%$ & $140 \%$ & $-43(\mathrm{M})$ & $-81(\mathrm{H})$ \\
\hline 2 & $\begin{array}{c}\text { Date of } \\
\text { minimum }\end{array}$ & 37.5 & 9 & 38.5 & 4 & $3 \%$ & $56 \%$ & $9(\mathrm{~L})$ & $-29(\mathrm{M})$ \\
\hline & $\begin{array}{c}\text { Date of } \\
\text { maximum }\end{array}$ & 212.5 & 208 & 214.5 & 210 & $69 \%$ & $1 \%$ & $-21(\mathrm{~L})$ & $-29(\mathrm{M})$ \\
\hline & $\begin{array}{c}\text { Low pulse } \\
\text { count }\end{array}$ & 4 & 35 & 8 & 34 & $25 \%$ & $3 \%$ & $-43(\mathrm{M})$ & $-33(\mathrm{M})$ \\
\hline & $\begin{array}{l}\text { Low pulse } \\
\text { duration }\end{array}$ & 5 & 2 & 2 & 2 & $25 \%$ & 0 & $-21(\mathrm{~L})$ & $3(\mathrm{~L})$ \\
\hline & $\begin{array}{l}\text { High pulse } \\
\text { count }\end{array}$ & 8 & 36 & 10 & 38 & $8 \%$ & $6 \%$ & $-38(\mathrm{M})$ & $-39(\mathrm{M})$ \\
\hline & $\begin{array}{l}\text { High pulse } \\
\text { duration }\end{array}$ & 4 & 2 & 3 & 2 & $38 \%$ & 0 & $-9(\mathrm{~L})$ & $-3(\mathrm{~L})$ \\
\hline & Rise rate & 141 & 0.8 & 130 & 0.811 & $22 \%$ & $1 \%$ & $-21(\mathrm{~L})$ & $-22(\mathrm{~L})$ \\
\hline & Fall rate & -108.5 & -0.79 & -150 & -0.789 & $17 \%$ & 0 & $-100(\mathrm{H})$ & $78(\mathrm{H})$ \\
\hline & $\begin{array}{l}\text { Number of } \\
\text { reversals }\end{array}$ & 151 & 218 & 184 & 215 & $21 \%$ & $1 \%$ & $-89(\mathrm{H})$ & $-38(\mathrm{M})$ \\
\hline
\end{tabular}

Note: H-High Variability; M-Moderate Variability Limit; L-Low Variability.

(6) The overall degree of alteration of flow and precipitation. Figure 3 shows the diagram of the hydrological alteration degree of the high field station. It can be seen from the figure that there are four high alterations, 15 medium alterations, and the rest are low alterations in the hydrological alteration degree index in the Min River basin. Among the precipitation alteration indexes in the Min River basin, except for the average precipitation in July, the baseflow index, and the decline rate, which was highly altered, the rest were all moderate and low altered.

According to the above equation, the 32 hydrological indicators of alteration are integrated (Figure 2) to find out the overall hydrological alteration of the lower Min River basin. The overall degree of alteration in flow is moderate alteration. The overall alteration of precipitation is $37 \%$ moderate alteration, and the degree of alteration is small. It shows that climate alteration is not the dominant factor affecting the alteration of Min River streamflow (Table 3; Figure 3).
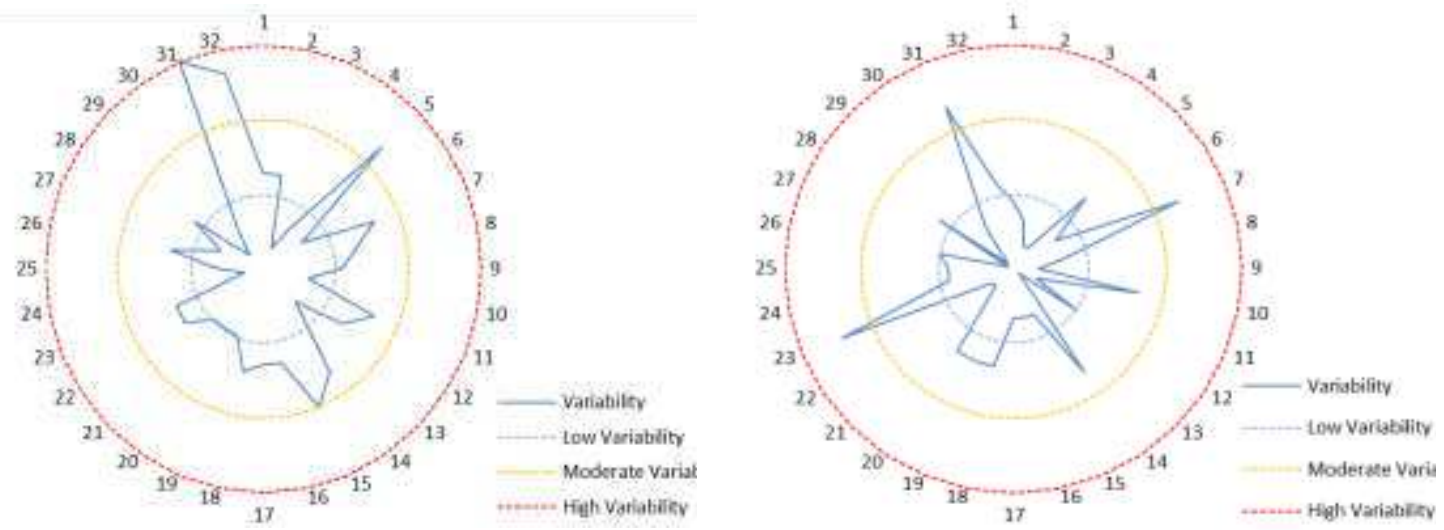
Fig.2 Schematic diagram of hydrological alteration degree of Gaochang Station
Fig.3 Schematic diagram of precipitation alteration degree in Min River Basin

Table.3 Min River discharge and precipitation overall alteration degree

\begin{tabular}{ccccccc}
\hline \multirow{2}{*}{ Category } & \multicolumn{4}{c}{ Hydrology, precipitation alteration degree } & Overall degree \\
\cline { 2 - 5 } & Group 1 & Group 2 & Group 3 & Group 4 & Group 5 & of alteration $\mathrm{D}_{0}$ \\
\hline Gaochang Station & $43(\mathrm{M})$ & $43(\mathrm{M})$ & $16(\mathrm{~L})$ & $31(\mathrm{M})$ & $78(\mathrm{H})$ & $45(\mathrm{M})$ \\
Min river precipitation & $32(\mathrm{~L})$ & $39(\mathrm{M})$ & $29(\mathrm{~L})$ & $26(\mathrm{~L})$ & $52(\mathrm{M})$ & $37(\mathrm{M})$ \\
\hline
\end{tabular}

Note: H-High Variability; M-Moderate Variability; L-Low Variability.

\section{Analysis of alterations in runoff conditions}

In the selected hydrological series of the Min River basin, the annual runoff volume alterations with some oscillations and is unstable, with a slight upward trend in the $\mathrm{T}_{\mathrm{a}}$ stage and a significant downward trend in the $\mathrm{T}_{\mathrm{b}}$ stage, and the annual runoff volume has a decreasing trend in general; according to the trend test analysis, the test statistic is -2.76 , which passes the $95 \%$ significance level test; the maximum value of annual runoff volume is $1004.54 \times 108 \mathrm{~m}^{3} / \mathrm{s}(1990)$, and the minimum value is $635.17 \times 108 \mathrm{~m}^{3} / \mathrm{s}$ (2006); compared with the $\mathrm{T}_{\mathrm{a}}$ period, the annual runoff in the $\mathrm{T}_{\mathrm{b}}$ period decreases by $10.46 \%$. The yearly precipitation is falling in both $\mathrm{T}_{\mathrm{a}}$ and $\mathrm{T}_{\mathrm{b}}$ periods, and according to the trend test statistic of -1.52 , the trend is not significant, and the decrease is not evident in many years; the maximum value of annual precipitation is $1286.78 \mathrm{~mm}(1990)$, and the minimum value is $808.17 \mathrm{~mm}$ (2006); compared with the $T_{a}$ period, the yearly rainfall in $T_{b}$ period decreases by $6.33 \%$. The fluctuation of annual evapotranspiration is more dramatic, with an apparent decreasing trend in the $T_{a}$ stage and a slight increase in the $T_{b}$ stage after the breakthrough, with an overall decreasing trend (Figure 4; Figure 5).

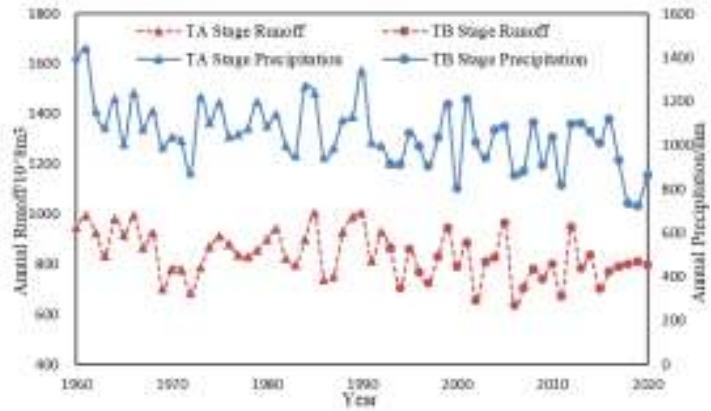

Fig.4 Trend chart of annual runoff and annual precipitation in Min River Basin before and after the sudden alteration

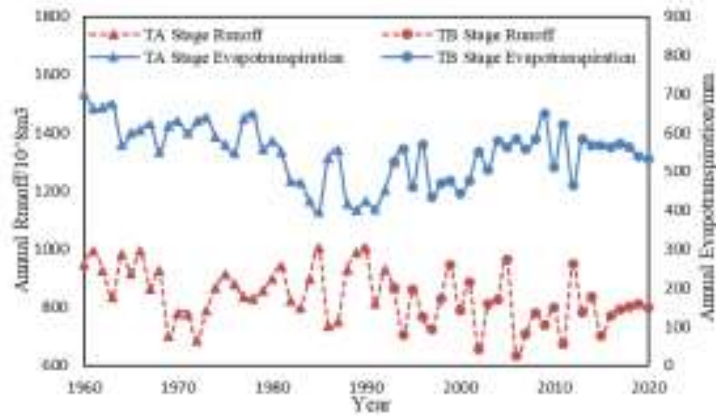

Fig.5 Trend chart of annual runoff and annual evapotranspiration in the Min River Basin before and after the breakthrough

The calculated results of runoff situation alterations in Table 4 show the degree of influence of climate alteration and human activities on annual dimensions. The elasticity coefficient of runoff to precipitation is 0.83 ; the contribution of climate alteration and human activities to the runoff alteration is $30.20 \%$ and $69.80 \%$, respectively.

Table. 4 Calculation results of alterations in runoff regime

\begin{tabular}{cccccccc}
\hline Index & Zhang & $\mathrm{Fu}$ & Schireiber & Budyko & Pike & Ol'dekop & Mean \\
\hline$\varepsilon p$ & 0.59 & 0.92 & 0.93 & 0.63 & 0.94 & 0.96 & 0.83 \\
$\Delta Q_{c} / m m$ & -22.94 & -28.16 & -28.54 & -23.79 & -28.68 & -28.89 & -26.83 \\
$\Delta Q_{H} / m m$ & -65.92 & -60.70 & -60.32 & -65.07 & -60.18 & -59.97 & -62.03 \\
$\eta_{C} / \%$ & 25.82 & 31.69 & 32.11 & 26.77 & 32.27 & 32.51 & 30.20 \\
$\eta_{H} / \%$ & 74.18 & 68.31 & 67.89 & 73.23 & 67.73 & 67.49 & 69.80 \\
\hline
\end{tabular}


The multi-year precipitation in the Min River basin is on a downward trend, but the overall decline is not significant. We know that the annual runoff of the Min River also shows a decreasing trend, which indicates that the alteration of precipitation will have a certain impact on the annual runoff. The Min River is rich in water and ecological resources. In recent years, the number of human exploitation of the Min River's hydropower resources has increased significantly, and the number of reservoirs and their capacity has gradually risen. People have made full use of the abundant water resources in the Min River basin to build reservoirs, store water during the flood season and release water during the dry season for the benefit of both sides of the river. By the end of 2019, Min River has built more than 870 large and small reservoirs, with a cumulative total capacity of about 15.3 billion $\mathrm{m}^{3}$, and 22 reservoirs are currently under construction in the basin, with a total capacity of about 3.88 billion $\mathrm{m} 3$. In the high field control area, Gongzui and Tongjiezi Reservoirs were put into operation in 1972 and 1993; Zipingpu Reservoir and Waterfall Ditch Reservoir were put into operation in 2006 and 2009, respectively. The terraced power station has brought a more significant impact on the ecological environment in the watershed and has a more significant impact on runoff. Water storage in reservoirs often leads to seepage, which causes certain losses, and reservoir storage will lead to increased water use, and part of the water will evaporate in the process of water use, changing the intra-annual distribution and hydrological pattern of runoff in the Min River basin. The human activity factor dominates the runoff alteration process. The use of human activities for water allocation, power generation, and shipping in the study area should be actively considered to promote the water's ecological benefits.

\section{Discussion}

\section{Impact of climatic factors on runoff}

Precipitation is the main source of runoff, and its variability has a direct impact on runoff. The rainfall-runoff deep double accumulation curve is a straight line in the natural state, which will be shifted if natural alterations such as extreme precipitation occur. Relative to the base period, the slope of the abrupt alteration period in the Min River basin shows a decreasing trend, i.e., the rainfall-runoff depth double accumulation curve is shifted downward, indicating that the runoff decreases under the same rainfall (Figure 6), so precipitation has a particular influence on the alteration of runoff in the basin, but it is not a key influencing factor ${ }^{25}$. The slope of the potential evapotranspiration also tends to decrease after the abrupt alteration, and the potential evapotranspiration-runoff depth double accumulation curve shifts downward somewhat (Figure 7). The correlation coefficient between runoff depth and potential evapotranspiration has a decreasing trend, which shows that the correlation between potential evapotranspiration and runoff depth is weak, so the influence of potential evapotranspiration on runoff alterations is small ${ }^{26,27}$. It shows that the runoff alteration in the watershed is mainly caused by human activities.

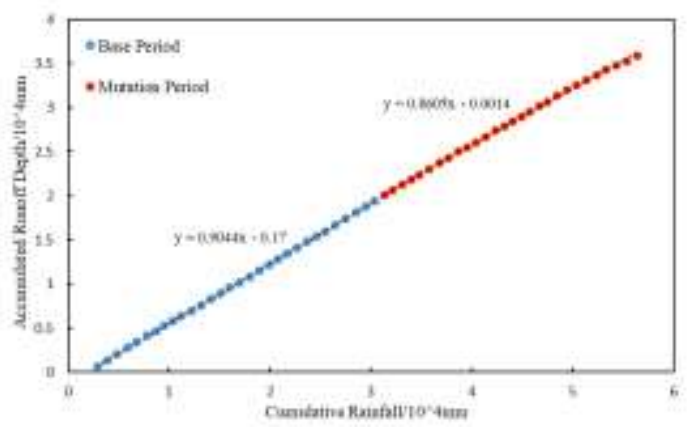

Fig.6 Precipitation-Runoff depth double

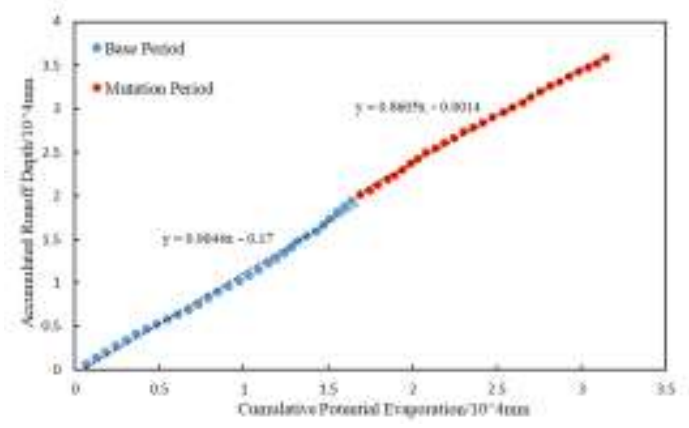

Fig.7 Potential evaporation-Runoff depth 
accumulation curve in Min River Basin

double accumulation curve in Min River Basin

\section{Impact of land-use change on runoff changes in the watershed}

Using five phases of remote sensing data in the study area, ArcGIS was applied to map the land-use changes in the Min River basin in different periods (1980, 1990, 2000, 2010, 2020) (Figure 8) and analyze the changes in land-use area increase and decrease in different periods. According to the characteristics of land-use types, the realm study area is divided into six categories: forest, grassland, cropland, wetland, barren land, and construction land. In recent years, the rapid development of population and economy in the Yangtze River basin has led to a change in vegetation cover. The vegetation cover had improved since 1989 when the state started to take various soil and water conservation engineering measures in the Yangtze River basin ${ }^{28}$.

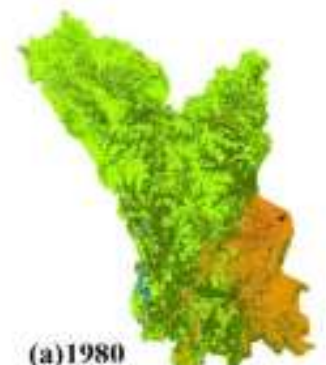

(a) 1980

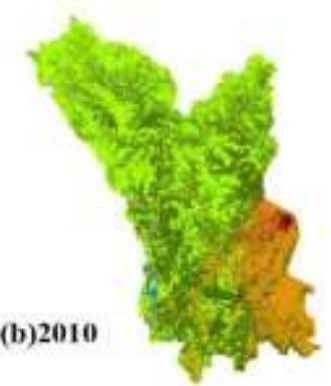

(b) 1990

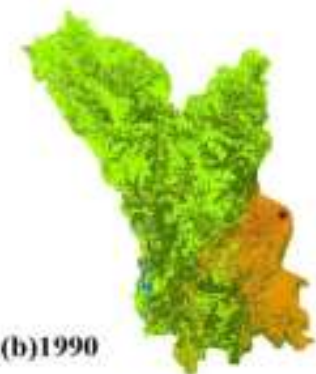

(b) 2020

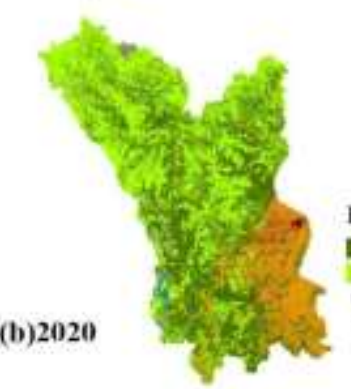

Fig. 8 Land use map in different periods of the Min River Basin

The land cover change in Min River Basin from 1980 to 2020 shows fluctuating changes, the grassland area coverage increases from $42.15 \%$ to 42.58 , and the increased area is $105 \mathrm{~km}^{2}$ (Table 5); the increase in construction land changes more between 1980 and 2020, and the area increase rate is $0.23 \%$, which indicates that with the continuous development of industrialization and urbanization, the construction land area increases gradually with time; the un The trend of decrease and then increase in a barren land, and the decrease in the forest, cropland, and wetland area indicate that human activities have had an impact on the habitats in the watershed. In recent years, human activities in the Min River basin have increased significantly, leading to a rapid increase in the proportion of land used for construction and a decrease in wetland areas ${ }^{29,30}$.

Table.5 Changes of Land Use Types in Different Periods in the Yangtze River Basin

\begin{tabular}{|c|c|c|c|c|c|c|}
\hline \multirow{2}{*}{ Land Type } & \multicolumn{5}{|c|}{ Area ratio $\%$} & \multirow{2}{*}{$\frac{\text { Area change rate } \%}{1980-2020}$} \\
\hline & 1980 & 1990 & 2000 & 2010 & 2020 & \\
\hline Grassland & 42.51 & 42.54 & 42.64 & 42.76 & 42.58 & 0.07 \\
\hline Forest & 38.17 & 38.14 & 38.04 & 38.01 & 38.00 & -0.17 \\
\hline Cropland & 15.8 & 15.74 & 15.57 & 15.19 & 15.57 & -0.23 \\
\hline Barren land & 2.03 & 2.05 & 2.05 & 2.07 & 2.15 & 0.12 \\
\hline Construction land & 0.78 & 0.84 & 1.01 & 1.25 & 1.01 & 0.23 \\
\hline Wetland & 0.71 & 0.69 & 0.69 & 0.72 & 0.69 & -0.02 \\
\hline
\end{tabular}


The evolution of land types and land-use patterns in the Min River basin are analyzed (Table 6). the watershed area decreases by $9 \mathrm{~km}^{2}$ during 1980-2020, mainly to grassland and barren land, indicating the severity of soil erosion. Since the implementation of soil and water conservation measures in 1980, the forested area showed a trend of growth followed by a decrease during this period. With the development of hydropower projects and the dramatic increase of human activities, the total forested area remained in a decreasing change, decreasing by $230 \mathrm{~km}^{2}$. Grassland and construction land increased by $100 \mathrm{~km}^{2}$ and $321 \mathrm{~km}^{2}$, respectively, with the most dramatic increase in the construction area during 1980-2020.

Table.6 Transfer matrix of land use from 1980 to $2020\left(\mathrm{~km}^{2}\right)$

\begin{tabular}{ccccccccc}
\hline \multirow{2}{*}{ Period } & Land Type & \multicolumn{7}{c}{2020} \\
\cline { 3 - 8 } & & Cropland & Grassland & Forest & Construction land & Wetland & Barren land & total \\
\hline \multirow{4}{*}{ Cropland } & 21112 & 24 & 32 & 316 & 16 & 0 & 21500 \\
& Grassland & 12 & 56302 & 1129 & 4 & 18 & 381 & 57846 \\
& Forest & 53 & 1347 & 50519 & 4 & 14 & 10 & 51947 \\
\cline { 3 - 8 } & Construction land & 2 & 1 & 2 & 1049 & 0 & 0 & 1054 \\
& Wetland & 10 & 20 & 8 & 2 & 911 & 17 & 968 \\
& Barren land & 0 & 252 & 27 & 0 & 0 & 2490 & 2769 \\
& total & 21189 & 57946 & 51717 & 1375 & 959 & 2898 & 136084 \\
\hline
\end{tabular}

The mechanisms by which land-use change affects runoff processes in a watershed are complex. One of the most direct effects of land-use change on runoff is soil erosion and implementing soil and water conservation measures to protect against water and sand reduction. Land-use changes have a direct impact on the watershed substrate and are related to the process of watershed flow production and confluence, which leads to changes in the watershed runoff. The decrease of cropland and forest, and the increase of construction land, i.e., the increase of impermeable layer in the watershed sub-base, will impact runoff, precipitation, and evaporation, thus changing the spatial and temporal distribution of water resources ${ }^{31,32}$. Land-use change in the Min River basin is an essential factor in the change of runoff in the basin, but the extent of its influence due to is less than the extent of the influence of the construction of water conservancy projects on the change of runoff in the Min River basin ${ }^{33}$.

\section{Conclusion}

(1) Through the Mann-Kendall method, the cumulative anomaly method, and the sliding T-test method combined with the reservoir construction, the abrupt year of runoff and precipitation was 1993. Annual runoff, precipitation, and evapotranspiration show a downward trend.

(2) Using the RVA method to conduct a comprehensive analysis of 32 hydrological indicators and 32 precipitation indicators in the Min River basin hydrological stations, the overall hydrological alteration at the Gaochang hydrological station is $45 \%$ is a moderate alteration. Considering the influence of precipitation on the alteration of runoff, the overall alteration of rain in the Min River basin is $37 \%$, which is a moderate alteration. Climate factors have less influence on runoff alterations. At the same time, human activities such as water conservancy construction have brought resources and convenience to people and also caused alterations to the hydrological situation in the basin, thus causing damage to the ecological function of rivers and alterations to the habitat of aquatic organisms.

(3) The contribution rates of climate alteration and human activities to the Min River runoff 
were $30.20 \%$ and $69.80 \%$, respectively. Human activities were the dominant factors influencing the Min River basin runoff situation.

(4) The Min River basin has seen an increase of $321 \mathrm{~km}^{2}$ in a built-up area and a corresponding decrease in the water area, forest area, and cropland area in the land use type from 1980 to 2020, and land-use changes in the Min River basin have become a factor leading to runoff changes in the area that cannot be ignored.

\section{Materials and Methods \\ Study area}

The Min River is a first-class tributary on the upper left bank of the Yangtze River, originating at the southern foot of Min Mountain in Songpan, Sichuan, and is rich in freshwater fishery resources. As an essential source of water resources for the Chengdu Plain, the Min River has the Dujiangyan Water Conservancy Project, which provides the foundation for forming the " Land of Abundance," It covers an area of 23,037 square kilometers. A large tributary of the Min River basin is the Dadu River, which is formed by the confluence of the upper reaches of the Min River, the Qingyi River, and the Dadu River ${ }^{34}$. The lower reaches of the Min River are an essential habitat for fish and an important channel to communicate with the middle and upper reaches of the Min River and the Dadu River. The Gaochang hydrological station, which is the subject of this study, is located at the confluence of the Dadu River and the Min River and is situated in the lower reaches of the Min River, so the streamflow data from the Gaochang hydrological station are representative ${ }^{35}$. With the development of science and technology and the improvement of human living standards, the development of the Min River basin has increased dramatically in recent years, and the water environment in the Min River basin has undergone significant alterations, with irreversible consequences on the ecological environment, especially the gradual construction of the upper Min River basin step-by-step power stations have brought a series of impacts on the runoff and fish resources of the lower Min River. Gongzui Reservoir was built on the Dadu River and started to store water in 1972, Tongjiezi Reservoir began to operate in 1993, causing significant alterations to the hydrological sequence within the control area of the high field station, and Zipingpu Reservoir, located in the upper reaches of the Min River, was put into operation in 2006, operating in parallel with the original reservoirs in the Min River basin.

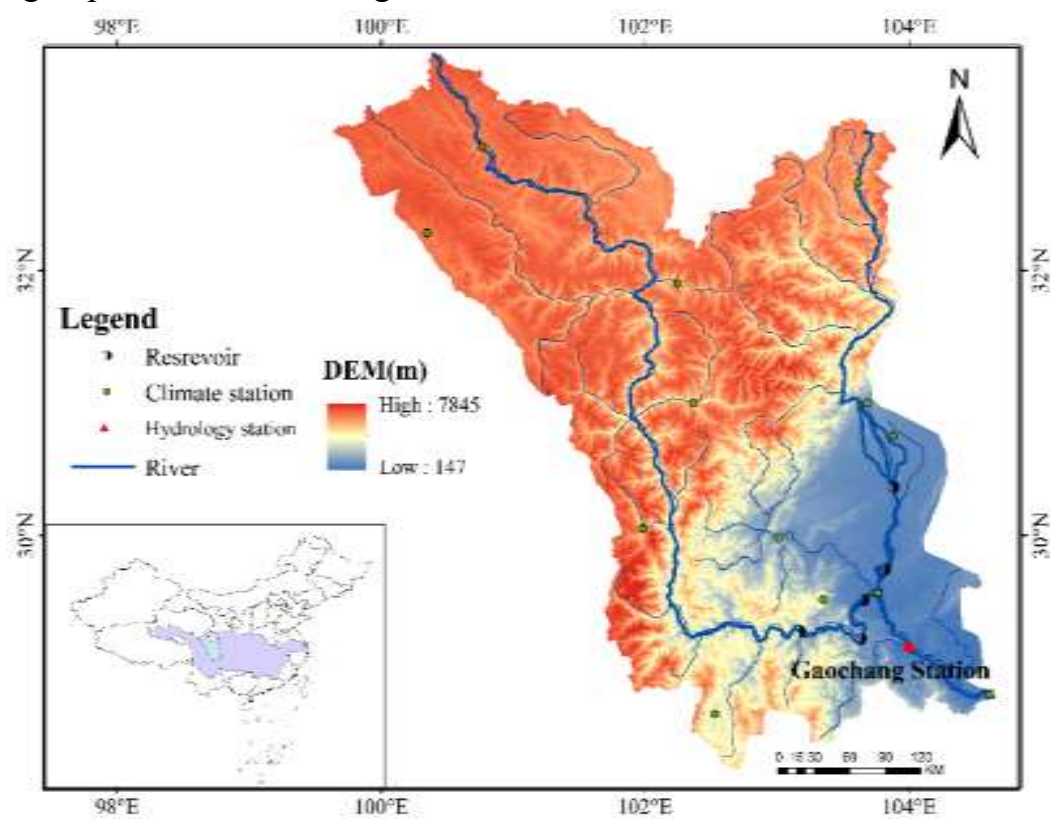




\section{Data}

Combining the distribution of hydrological and meteorological stations in the Min River basin, the study uniformly selected day-by-day meteorological element data from 13 meteorological stations in the Min River basin from 1960 to 2019, which are distributed throughout the Min River basin (Figure 9) and can represent the spatial alteration of hydro-meteorology in the basin. The meteorological data were obtained from the China Meteorological Data Network (http://data.cma.cn), and there were missing daily data from individual meteorological stations, and the study interpolated the missing data. Considering the distribution of rivers within the Min River basin, the daily flow data from 1960-2019 at Gaochang Station, a representative hydrological station at the confluence of the Dadu River, a tributary of the Min River, with the lower reaches of the mainstream, were selected from the Hydrological Yearbook of the Yangtze River Basin.

\section{Methods}

\section{Trend and mutation analysis}

The hydrological alteration process of the river is very complex, and in order to analyze the trend and sudden alteration tests of runoff alterations at the high field hydrological station and precipitation conditions within the Min River basin, the Mann-Kendall test, the cumulative distance level method, and the sliding T-test method are mainly used in this study. The detailed calculation procedures are described in $\operatorname{Ref}^{36,37}$.

\section{IHA-RVA method}

To quantitatively analyze the degree of influence of reservoir construction in the Min River basin on the hydrological situation of rivers, Richter et al. 1996 proposed 32 hydrological alteration indicators that can represent the relationship between river streamflow alterations and external ecological alterations, IHA indicators can express the degree of environmental influence on rivers, and then used the range of alteration method (RVA) established based on the hydrological alteration indicator method to evaluate the river Hydrological situation alteration situation. And the degree of alteration after the alteration was quantified by calculating the degree of alteration (Table 1) by the following equation ${ }^{38}$.

$$
D_{i}=\left|\frac{N_{o i}-N_{e}}{N_{e}}\right| \times 100 \%
$$

Where: $D_{i}$ is the degree of hydrological alteration of the $i$ the IHA indicator; $N_{0 i}$ is the number of years that fall within the RVA target threshold for the $i$ IHAs observed after the disturbance; $N_{e}$ is the number of years after the alteration.

The hydrological degree of alteration of individual indicators cannot reflect the overall degree of alteration, so this paper uses the overall degree of hydrological alteration $D_{o}$ to reflect the overall alteration of water temperature, the calculation principle is detailed in the literature, the following formula is calculated.

$$
D_{O}=\left(\frac{1}{n} \sum_{i=1}^{n} D_{i}^{2}\right)^{0.5}
$$

Where: $n$ is the number of indicators. The comprehensive index hydrological alteration degree $D_{o}$ can fully reflect the overall alteration, the absolute values of the hydrologic alteration degree (0-100\%) were divided into three categories: (1) 0-33\% represented low or no Variability (L); (2) 33-67\% represented moderate Variability (M); and (3) 67-100\% represented high Variability (H), as shown in Table 7. 


\begin{tabular}{ccc}
\hline Method & Classification & Influence Level \\
\hline \multirow{2}{*}{ RVA } & $0-33 \%$ & Low Variability \\
& $33-67 \%$ & Moderate Variability \\
& $67-100 \%$ & High Variability \\
\hline
\end{tabular}

\section{Estimation of potential evaporation}

In this study, the potential evapotranspiration was calculated using the FAO Penman-Monteith formula, which has been widely used by domestic and international scholars ${ }^{39}$.

$$
E T_{0}=\frac{0.408\left(R_{n}-G\right)+\gamma \frac{900}{T+273} \mu_{2}\left(e_{s}-e_{a}\right)}{\Delta+\gamma\left(1+0.34 \mu_{2}\right)}
$$

Where: $E T_{0}$ is the potential evaporation $(\mathrm{mm} / \mathrm{d}) ; \Delta$ is the slope of the saturation water pressure curve $\left(\mathrm{Kpa} /{ }^{\circ} \mathrm{C}\right) ; R_{n}$ is the net surface radiation $\left(\mathrm{MJ} / \mathrm{m}^{2} \mathrm{~d}\right) ; \quad G$ is the soil heat flux $\left(\mathrm{MJ} / \mathrm{m}^{2} \mathrm{~d}\right) ; \gamma$ is the dry and wettable constant $\left(\mathrm{Kpa} /{ }^{\circ} \mathrm{C}\right) ; T$ is the average daily air temperature $\left({ }^{\circ} \mathrm{C}\right) ; \mu_{2}$ is the wind speed at $2 \mathrm{~m}(\mathrm{~m} / \mathrm{s}) ; e_{s}$ is the saturation water pressure $(\mathrm{KPa}) ; e_{a}$ is the actual water pressure $(\mathrm{KPa})$. The above meteorological data were obtained from China Meteorological Data Network, and the specific calculation process is shown in Ref.

\section{Quantitative Analysis of Runoff Situation Alterations}

alterations in runoff within the Min River basin should take both climate and human activities into account, calculated as

$$
\begin{gathered}
\Delta Q=\Delta Q_{C}+\Delta Q_{H} \\
\eta_{C}=Q_{C} / \Delta Q \times 100 \% \\
\eta_{H}=\Delta Q_{H} / \Delta Q \times 100 \%
\end{gathered}
$$

Where: $\Delta Q$ is the difference of streamflow alteration; $\Delta Q_{C}$ and $\Delta Q_{H}$ are the amount of runoff alteration caused by climate alteration and human activities; $\eta_{C}$ and $\eta_{H}$ are the contribution rate of climate alteration and human activities ${ }^{40,41}$.

The elasticity coefficient method was chosen to calculate $\Delta Q_{C}$ and $\Delta Q_{H}$ based on the basin long time water balance equation $\left(Q=P-E_{\alpha}\right)$, the dryness index $\left(\phi=E_{0} / P\right)$ calculation, and six formulas based on Budyko's assumptions (Table 2), with the following equations.

$$
\begin{gathered}
\Delta Q_{C}=\varepsilon_{P} \frac{Q}{P} \Delta P+\varepsilon_{E_{0}} \frac{Q}{E_{0}} \Delta E_{0} \\
\varepsilon_{P}=1+\frac{\phi F^{\prime}(\phi)}{1-F(\phi)}, \text { and } \varepsilon_{E_{0}}=1-\varepsilon_{P}
\end{gathered}
$$

Where: $Q, E_{0}$, and $P$ are the multi-year average runoff, potential evapotranspiration, and precipitation, respectively; $\Delta E_{0}$ and $\Delta P$ are the alterations in potential evapotranspiration and precipitation before and after the impact, respectively; and $\varepsilon_{P}$ and $\varepsilon_{E_{0}}$ are the elasticity indices of runoff to precipitation and potential evapotranspiration, respectively. For the 6 formulas $F(\phi)$ and $F^{\prime}(\phi)$ based on Budyko's hypothetical formula, refer to related literature ${ }^{42,43}$ (Table 8).

Table.8 6 common expressions based on Budyko's hypothesis

\begin{tabular}{cccc}
\hline $\begin{array}{c}\text { Serial } \\
\text { number }\end{array}$ & $F(\phi)$ & $F^{\prime}(\phi)$ & $\begin{array}{c}\text { Literature } \\
\text { Source }\end{array}$ \\
\hline 1 & $(1+\omega \phi) /(1+\omega \phi+1 / \phi), \omega=1$ & $\left(\omega+2 \omega / \phi-1+1 / \phi^{2}\right) /(1+\omega \phi+1 / \phi)^{2}$ & Zhang; 2001 \\
2 & $1+\phi-\left(1+\phi^{a}\right)^{1 / a}, a=2.5$ & $1-\left(1+\phi^{a}\right)^{1 / a-1} \phi^{a-1}$ & Baopu Fu; 1981 \\
3 & $1-e^{-\phi}$ & $e^{-\phi}$ & Schireiber; 1904
\end{tabular}




\begin{tabular}{|c|c|c|c|}
\hline 4 & {$\left[\phi \tanh (1 / \phi)\left(1-e^{-\phi}\right)\right]^{0.5}$} & $\begin{array}{l}0.5\left[\phi \tanh (1 / \phi)\left(1-e^{-\phi}\right)\right]^{-0.5} \times[\tanh (1 / \phi)- \\
\left.\operatorname{sech}^{2}(1 / \phi) / \phi\left(1-e^{-\phi}\right)+\phi \tanh (1 / \phi) e^{-\phi}\right]\end{array}$ & Budyko; 1948 \\
\hline 5 & $\left(1+\phi^{-2}\right)^{-0.5}$ & $1 /\left[\phi^{3}\left(1+(1 / \phi)^{2}\right)^{1.5}\right]$ & Pike; 1964 \\
\hline 6 & $\phi \tanh (1 / \phi)$ & $\tanh (1 / \phi)-4 /\left[\phi\left(e^{-1 / \phi}+e^{1 / \phi}\right)^{2}\right]$ & Ol'dekop; 1911 \\
\hline
\end{tabular}

\section{References}

397 1. Gao, B., Yang, D., Zhao, T. \& Yang, H. Changes in the eco-flow metrics of the upper yangtze river 398 from 1961 to 2008. Journal of Hydrology. 448-449, 30-38(2012).

399 2. Yuan Y. et al. Quantitative assessment of the contribution of climate variability and human activity 400 to streamflow alteration in dongting lake, china. Hydrological Processes. 30(12), 401 1929-1939(2016).

402 3. Richter, B. D., Baumgartner, J. V., Powell, J. \& Braun, D. P. A method for assessing hydrologic 403 alteration within ecosystems. Conservation Biology. 10(4), 1163-1174(1996).

404 4. Nilsson, C. \& Svedmark, M. Basic principles and ecological consequences of changing water 405 regimes: riparian plant communities. Environmental Management. 30(4), 468-480(2002).

406 5. Stalnaker, C., Lamb, B. L., Henriksen, J., Bovee, K. \& Bartholow, J. The instream flow 407 incremental methodology: a primer for IFIM. department of interior national biological service 408 biological report. (1995).

409 6. Rong, X., Lw, A., Hong, L. A., Zt, A. \& Bza, B. Temporal and spatial variation in water quality in 410 the three gorges reservoir from 1998 to 2018. Science of The Total Environment. 768, 411 144866-144877(2020).

412 7. Huang, J., Yang, W., Yang, X. \& Deng, Bing. The Influence of Eco-water Retrieved by 413 Quantitative Remote Sensing on Runoff in Upper Minjiang River Basin. Earth Sciences Research 414 Journal. 20(3), 1-6(2016).

415 8. Lu, C., Jin Z., Lin M., Li Q. \& Wang, Y. Impact of Rrstrvoir Construction on Water and Sediment 416 Transport in Minjiang River Basin,China. Journal of Yangtze River Scientific Research Institute. 417 37(08), 9-15+21(2020).

418 9. Gao, Y., Chen, L., Zhang, W., Li, X. \& Xu, Q. Spatiotemporal variations in characteristic 419 discharge in the yangtze river downstream of the three gorges dam. Science of The Total 420 Environment. 785(3-4), 147343(2021).

421 10. Han, J., Sun, Z., Li, Y. \& Yang, Y. Combined effects of multiple large-scale hydraulic engineering 422 on water stages in the middle yangtze river. Geomorphology. 298, 31-40(2017).

423 11. Richter, B. D., Baumgartner, J., Wigington, R. \& Braum, D. How much water does a river need. 424 Freshwater Biology. 37(1), 231-249(1997).

425 12. Richter, B. D. \& Thomas. G. A. Restoring Environmental Flows by Modifying Dam Operations. 426 Ecology and Society. 12(1), 12(2007).

427 13. Gao, B., Li, J. \& Wang, X. Analyzing Changes in the Flow Regime of the Yangtze River Using the 428 Eco-Flow Metrics and IHA Metrics. Water. 10(11), 1552(2018).

429 14. Guo, W., Dou, G., Wang, H. \& li, Y. Quantitative Evaluation of the Impact of Precipitation and 430 Human Activities on Sediment Regime in the Middle and Lower Reaches of the Yangtze River in 431 Recent Sixty Years, China. Journal of Basic Science and Engineering. 29(01), 39-54(2021).

432 15. Xia, J., Ma, X., Zou, L., Wang, Y. \& Jing, Z. Quantitative analysis of the effects of Climate change 433 and human activities on runoff in the Upper Hanjiang River basin, China. South-to-North Water 434 Transfers and Water Science \& Technology. 15(01), 1-6(2017). 
435 16. Peng, T. et al. Quantitative assessment of drivers of sediment load reduction in the Yangtze River 436 basin, China-ScienceDirect. Journal of Hydrology. 580(C), 124242-124259(2020).

437 17. Shen, Q., Cong, Z. \& Lei, H. Evaluating the impact of climate and underlying surface change on 438 runoff within the Budyko framework: A study across 224 catchments in China. Journal of 439 Hydrology. 554, 251-262(2017).

440 18. Zhao, G. et al. Quantifying the impact of climate variability and human activities on streamflow in 441 the middle reaches of the Yellow River basin, China. Journal of Hydrology. 519, 387-398(2014).

442 19. Li, F., Zhang, G. \& Xu Y. Separating the Impacts of Climate Variation and Human Activities on 443 Runoff in the Songhua River Basin, Northeast China. Water. 6(11), 3320-3338(2014).

444 20. Hou, J., Ye, A., You, J., Ma, F. \& Duan, Q. An estimate of human and natural contributions to 445 changes in water resources in the upper reaches of the Minjiang River. The Science of the Total 446 Environment. 635, 901-912(2018).

44721 . Ma, K. et al. Effect of land use/cover changes on runoff in the Min River watershed. River 448 Research and Applications. 36(5), 749-759(2020).

449 22. Guo, W., Xu, G., Shen, J. \& Du, T. Research on runoff variation trend and hydrological situation 450 variation in Minjiang River Basin, China. Yangtze River. 49(22), 64-68(2018).

45123 . Zhou, Y. et al. Distinguishing the multiple controls on the decreased sediment flux in the Jialing 452 River basin of the Yangtze River, Southwestern China-ScienceDirect. CATENA. 193, 453 104593-104604(2020).

454 24. Nie, N., Zhang, W., Liu, M., Chen, H. \& Zhao D. Separating the impacts of climate variability, 455 land-use change and large reservoir operations on streamflow in the Yangtze River basin, China, 456 using a hydrological modeling approach. International Journal of Digital Earth. 18, 1-19(2020).

45725 . Zhao, G. et al. Quantifying the impact of climate variability and human activities on streamflow in 458 the middle reaches of the Yellow River basin, China. Journal of Hydrology, 519, 387-398(2014).

459 26. Wei, R., Liu, Y., Zhang, T. Zeng, Q. \& Dong, X. Attribution Analysis of Runoff Variation in the 460 Upper-Middle Reaches of Yalong River,China. Resources and Environment in the Yangtze Basin. 461 29(07), 1643-1652(2020).

462 27. Zhang, Q., Sun, P., Jiang, T., Tu, X. \& Chen X. Spatio-temporal patterns of hydrological processes 463 and their responses to human activities in the Poyang Lake basin, China. Hydrological Sciences 464 Journal. 56(2), 305-318(2011).

465 28. Wen, Z., Wu, S., Chen, J. \& Lu, M. NDVI indicated long-term interannual changes in vegetation 466 activities and their responses to climatic and anthropogenic factors in the Three Gorges Reservoir 467 Region, China. The Science of the Total Environment. 574, 947-959(2017).

46829 . Xu, J. et al. Seasonal variations of water quality response to land use metrics at multi-spatial 469 scales in the Yangtze River basin. Environmental Science and Pollution Research. 28(28), $470 \quad 37172-37180(2021)$.

471 30. Wan, L., Liu, H., Gong, H. \& Ren Y. Effects of Climate and Land Use changes on Vegetation 472 Dynamics in the Yangtze River Delta, China Based on Abrupt Change Analysis. Sustainability. 473 12(5), 1955-1975(2020).

474 31. Cui, X., Liu, S. \& Wei, X. Impacts of forest changes on hydrology: a case study of large 475 watersheds in the upper reaches of Minjiang River watershed in China. Hydrology and Earth 476 System Sciences, 16(11), 4279-4290(2012).

477 32. Zhang, H., Meng, C., Wang, Y., Wang, Y. \& Li M. Comprehensive evaluation of the effects of 478 climate change and land use and land cover change variables on runoff and sediment discharge. 
480 33. Xta, B. et, al. Changing land use and its impact on the habitat suitability for wintering 481 Anseriformes in China's Poyang Lake region-ScienceDirect. Science of The Total Environment. 482 557-558, 296-306(2016).

483 34. Li, J., Cai, C. \& Zhang, F. Assessment of Ecological Efficiency and Environmental Sustainability 484 of the Minjiang-Source in China. Sustainability. 12(11), 4783-4798(2020).

485 35. Li, C., Liu, S., Sun, P. \& Ge, J. Analysis on landscape pattern and eco-hydrological characteristics 486 at the upstream of Minjiang River, China. Acta Ecologica Sinica. 04, 691-698(2005).

487 36. Guo, W., Li, Y., Wang, H. \& Zha, H. Assessment of Eco-hydrological Regime of Lower Reaches 488 of Three Gorges Reservoir Based on IHA-RVA, China. Resources and Environment in the Yangtze 489 Basin. 27(09), 2014-2021(2018).

490 37. Sun, P., Sun, Y., Zhang, Q. \& Wen, Q. Temporal and spation variation characteristics of runoff 491 processes and its causes in Huaihe Basin, China. Journal of Lake Sciences.30(02), 497-508(2018).

492 38. Cheng, J., Xu, L., Fan, H. \& Jiang J. Changes in the flow regimes associated with climate change 493 and human activities in the Yangtze River. River Research and Applications. 35(9), 494 1415-1427(2019)

495 39. Li, Z., Zheng, F. \& Liu, W. Spatiotemporal characteristics of reference evapotranspiration during 496 1961-2009 and its projected changes during 2011-2099 on the Loess Plateau of China. 497 Agricultural and Forest Meteorology, 154, 147-155(2011).

498 40. Liang, W. et al. Quantifying the impacts of climate change and ecological restoration on 499 streamflow changes based on a Budyko hydrological model in China's Loess Plateau. Water 500 Resources Research, 51(8), 6500-6519(2015).

50141 . Tang, Q. et al. Determining the relative contributions of climate change and multiple human 502 activities to variations of sediment regime in the Minjiang River, China. Hydrological Processes, 503 27(25), 3547-3559(2013).

504 42. Wen, Z., Wu, S., Chen, J. \& Lu, M. NDVI indicated long-term interannual changes in vegetation 505 activities and their responses to climatic and anthropogenic factors in the Three Gorges Reservoir 506 Region, China. The Science of the Total Environment. 574, 947-959(2017).

$50743 . \mathrm{Xu}, \mathrm{J}$. et al. Seasonal variations of water quality response to land use metrics at multi-spatial 508 scales in the Yangtze River basin. Environmental Science and Pollution Research. 28(28), 509 37172-37180(2021).

\section{Acknowledgement}

511 We much appreciate the contributions of the experts who participated in this review. This study 512 was supported by the National Nature Science Foundation of China (Grant No. 51779094); Water 513 Conservancy Science and Technology Project of Guizhou Province (KT202008); The Wisdom 514 Introduction Project of Henan Province（GH2019032）.

\section{Author Contributions}

516 Wenxian Guo and Haotong Zhou: Data curation, Writing-original draft, Methodology, Funding a 517 cquisition. Yongwei Zhu and Xuyang Jiao: Conceptualization, Supervi-sion, Funding acquisition. 518 Hongxiang Wang: Conceptualization, Supervi-sion, Project administration. 


\section{Additional Information}

520 Competing Interests: The authors declare that they have no competing interests.

521 Publisher's note: Springer Nature remains neutral with regard to jurisdictional claims in publish

522 ed maps and institutional affiliations. 